\title{
La Estructura del Acontecimiento de "Los Perros Hambrientos"
}

Por ANTONIO CORNEJO POLAR

Las páginas que siguen intentan esclarecer la estructura del acontecimiento de "Los perros hambrientos". Tal análisis no nos permite sostener juicio alguno sobre la obra íntegra de Ciro Alegría, en la medida en que sólo a un aspecto de ella nos hemos aproximado. Sin Cembargo, parece exacto y justo afirmar, en calidad de hipótesis, que con las tres grandes novelas de Alegría ${ }^{1}$ culmina, con singular brillo, la primera etapa valiosa del irregular proceso de la novela peruana. Confirmar o rechazar este aserto es materia de la historia literaria y si, como quiere Wehrli, la "regeneración de la historia literaria será la próxima tarea de la ciencia de la literatura", pensamos que tal "regeneración" será producto de un imponderable esfuerzo de síntesis, por lo demás sólo posible sobre un andamiaje de monografías humildemente recortadas.

\section{ACCESO AL MUNDO NOVELISTICO}

"En la épica - dice Wolfgang Kayser, y su juicio se aplica sin duda a la novela, una de sus formas - la narración

1. "La serplente de oro". Santiago de Chile, Nascimiento, 1935; "Los perros hambrientos". Santiago de Chile, Zig-Zag, 1938; "El mundo es ancho y ajeno" Santiago de Chile, Ercilla, 1941. Prescindimos de la publicación muy posterior de "Duelo de caballeros"; (Lima, Populibros, i1963?; Buenos Aires, Losada, 1965). Las narraciones que confor-

2. Wehrli, Max: "Introducción a la clencla literarla", Buenos Aires, Nova, 1966, p. 181. 
sirve para crear un mundo"'3. Tal enunciado basta para enfrentarnos a una primera pregunta: ¿cómo accedemos al mundo novelístico?

En el caso de "Los perros hambrientos"4, aunque parezca paradójico, este acceso consiste en adoptar una situación marginal con relación al suceso, a los personajes y al ambiente de la obra. En efecto, desde la primera página, el lector siente entre él y el mundo novelístico la interpolación de un narrador que tiene por misión descubrir y explicar dicho mundo a un alguien indeterminado que, de antemano, se le reputa extraño.

Luego de una brevísima apertura descriptiva, nos enfrentamos con el siguiente párrafo:

Era una gran manada, puesto que se componía de cien pares, sin contar los corderos. Porque ha de saberse que tanto la Antuca, la pastora, como sus taitas y hermanos, contaban por pares. Su aritmética ascendia hasta ciento, para volver de alli al principio. Y así habrian dicho "cinco cientos" o "siete cientos" o "nueve cientos" pero, en realidad, jamás necesitaban hablar de cantidades tan fabulosas. Todavía, para simplificar aún más el asunto, iban en su auxilio los pares, enraizados en la contabilidad indígena con las fuertes raíces de la costumbre. Y después de todo, ¿para qué embrollar? Contar es faena de atesoradores, $y$ un pueblo que desconoció la moneda y se atuvo solamente a la simplicidad del trueque, es lógico que no èngendre descendientes de muchos números. Pero estas son, evidentemente, otras cosas. Hablábamos de un rebaño. (p. 171)

Es claro que el lector, cualquier lector, se siente alejado de un mundo que debe explicársele ("porque ha de saberse...") incluso un poco minuciosa y didácticamente ("y asi habrían dicho ..."). La presencia del narrador es, pues, desenfadada y el lector debe reconocer la necesidad de un guía - aunque lo hubiera preferido, creo, menos disgresivo. Lo importante es destacar el doble juego funcional que aquí se esconde: por una parte, el narrador muestra, descubre y explica el mundo novelesco; por otra, margina al lector de ese mismo mundo. El narrador se sitúa a sí mismo, por consiguiente, en el gozne sobre el que gira toda la experiencia de la lectura.

3. "Interpretaclón y análisis de la obra literaria", Madrid, Gredos, 1954, p. 563.

4. Cito por: "Novelas Completas", Madrid, Aguilar, '1953 (2da. edición). 
Algo similar sucede en "La serpiente de oro". Bien ha advertido Alberto Escobar que en esta novela el lector se siente "lector-forastero" , pero aquí se tiene la sensación de estar viendo una realidad nueva, e incluso el lector se presta los ojos de un viajero limeño que participa en la acción, mientras que en "Los perros hambrientos" se tiene la impresión de estar sólo escuchando un relato. En "La serpiente de oro" el lector es extraño al insólito mundo "que se le pone delante, pero se va introduciendo en él; en "Los perros hambrientos", en cambio, esta asimilación directa no se propicia como función del relato y el lector queda siempre en la situación de un oyente marginal. El alejamiento mundo novelescolector es, pues, mucho más profundo en el segundo caso $0^{6}$.

Algunos ejemplos, entresacados casi al azar de los dos primeros capítulos, esclarecerán lo dicho hasta aquí:

... ella gritaba:

- Nube, nubee, nubeeee...

Porque asi gritan los cordilleranos. Así, porque todas las cosas de la naturaleza pertenecen a su conocimiento y a su intimidad. (p. 176)

El Pancho la miraba hacer, complacido, y tocaba cualquier otra cosa. Así son los idilios en la cordillera. (p. 179)

¿Raza? No hablemos de ella, Tan mezclada como la del hombre peruano... (p. (185)

El nombre vinole a éste de su pelambre retorcido y enmarañado, pues shapra quiere decir motoso. (En el lenguaje cholo, algunas palabras keswas superviven injertadas en un castellano aliquebrado que sólo ahora comienza a ensayar vuelo). Shapra ladraba ... (pp. 187-188)

Con el correr del relato la explicitez de la presencia del narrador se va amenguando, aunque no llega a desaparecer $^{7}$. Paralelamente a esta disminución surge; cada vez con mayor claridad, una nueva actitud relativa a la con-

5. "La serpiente de oro o el rfo de la vida", en: "Patio de Letras", Lima, Caballo de

6. Troya, 1965 , p. 181. mejor la indole estructural de la novela.

7. Por ejemplo: "Es una pequeña planta de las alturas (la ratanya) cuya contorsionada raíz una vez machacada y hervida con la bayeta, tiñe a ésta de morado. Se usa mucho, y por eso $\in \mathrm{n}$ las regiones donde existe abunda ese color en los ponchos y polle:as". (p. 209). O también: "...se ingresaba por una tranquera de aguja. Se lama asi a la que consta de dos maderos paralelos, plantados en tier:a, que sostienen lar 
formación ciel mundo novelesco: o: la que la preceptiva llama "autor omniscicnte". El dislingo puede considerarse clifuso; sin embargo, el lector inture con claridad esta variante. Una cosa es seritirse a sí misno como oyente de un narrador que directa y desembozadamente cumple su función y otra, muy diversa, seguir un relato que proviene de un alguien impreciso que todo lo ve y todo lo sabe pero que, en ningún caso, afianza su función con ademanes personales e insoslayables.

Compárese cualquiera de los textos arriba citados, en los que la intromisión del narrador puede llegar a ser impertinente, con este otro:

El Damián, al negarse a aclarar la clesaparición de doña Candelaria, no hacía sino resistir con sus pequeñas fuerzas de niño al sorbo oscuro de la fatalidad. (p. 296)

Es también imprescindible advertir aquí, aunque luego habremos de detenernos en este mismo aspecto, que cventualmente el relato pasa a labios de los personajes, en especial de Simón Robles, el protagonista.

Ahora bien: ni los relatos de autor omnisciente ni los que están a cargo de los personajes consiguen mermar la importancia del narrador explícito y de la situación comunicativa a la que el lector tiene que someterse con respecto a aquél. $\mathrm{Y}$ esto es así tanto porque las intervenciones explicativas del narrador se van interpolando a lo largo de toda la novela, aunque con frecuencia decrediente, cuantó porque los primeros capítulos establecen con tal rotundidad la distancia entre el el lector y el mundo representado, a la par que fijan la función intermediaria del narrador, que resulta ya imposible romper posteriormente este andamiaje estructural.

\section{EL LENGUAJE DEL NARRADOR}

El narrador desea cumplir su misión de acuerdo a los viejos' cánones de los narradores populares:

Aprendiendo del Simón Robles, y frecuentemente ayudados por él mismo, relataremos también otras muchas importantes historias. (p. 191)

Este es un ideal estilístico reiteradamente expuesto por Ciro Alegría. En el Primer Encuentro de Narradores Peruanos, por ejemplo, el autor que estudiamos dijo: 
... mis primeras lecciones, mis primeras vivencias novelescas, las he vivido en el pueblo y las he aprendido del pueblo (...) Mis primeros maestros, aun antes de que yo supiera leer, fueron estos narradores populares, a los que honestamente he plagiado - un plagio honroso, creo yo. (8)

De sus maestros populares el narrador de "Los perros hambrientos" tiene el desembarazo y el sentirse a sí mismo como centro de la atención de los oyentes que hasta físicamente le rodean: de aquí la explicitez muchas veces ya dicha y el prurito de explicar las cosas, el regodeo en la interpolación sostenida, etc. Aquí también puede explicarse la libertad con la que es contada la anécdota, su parcelación, según tendremos oportunidad de confirmarlo más adelante.

Sin embargo, el lenguaje del narrador de "Los perros hambrientos" corresponde a una norma ${ }^{9}$ que no es estrictamente popular o que, al menos, se diferencia notablemente de la norma que usan los narradores populares dentro de la novela misma. Compárese cualquiera de los párrafos citados hasta aquí con este relato que está en labios de Simón Robles:

...pues hay una historia, yesta es quiuna viejita tenia dos perros: el uno se llamaba Guieso y el otro Pellejo. Y jué quiun día la vieja salió e su casa con los perros yentón llegó un ladrón y se metió bajo la cama .... (p. 190)

Con respecto a este paradigma de relato popular, los del narrador de "Los perros hambrientos" bien podrían concebirse pródigos en cultismos. No se trata, por supuesto, de la reproducción ortográfica de una elocución popular; se trata de la organización misma de la fabulación y de la frase narrativa. Formalmente bastaría advertir la secuencia totalmente polisindética del relato popular, por cierto inexistente y hasta imposible, en ese grado, dentro de los relatos del narrador.

Sucede que las "historias" de Simón Robles y otros personajes están a nivel cuasi folklórico (algunas son auténticos cuentos populares) y se transcriben con una intención puntillosamente realista, equivalente a la que camped asimismo en los fragmentos dialógicos de la novela:

8. Cit. poc el original de las Actas del Encuentro (tomadas a su vez de la grabación en cinta magnetofénica), todnvía inéditas, en poder de la Casa de la Cultura de

9. Cf. Coseriu, Eugenio. "Teoría del Lenguaje y Linguística General", Madrid, Gredos, 1962. 
- Guá, hom, ¿a qué ladran los perros?

- Dia e veras que yastán ladrando mucho. (p. 249)

O también:

- Pienso empuñar puallá, que ya vide viniendo onde hay unos alisos... ¿Qué piensasté?

- Gúeno... Aunque aura es güeno y malo..., pero, si llueve, resultará. (p. 272)

El lenguaje de los personajes y de los personajes-narradores no es el mismo, pues, que el del narrador. Despréndese de aquí la existencia de un nuevo hiato en la estructura de la novela, en cuanto el narrador mismo no pertenece al mundo novelado ${ }^{10}$. La existencia de las dos normas linguiisticas que comentamos significa, para el lector, el síntoma inequívoco de la no pertenencia del narrador al mundo representado. Esta comprobación termina por definir el esquema total de la narración de "Los perros hambrientos".

Hay que advertir que la norma lingüistica de los perso. najes-narradores no es, en modo alguno, una "traducción" del quechua - como hasta cierto punto sucede en las obras de José María Arguedasil. Esto fue establecido tajantemente por el propio Ciro Alegría. En artículo no muy lejano, y a propósito de unas declaraciones de Mario Vargas Llosa ${ }^{12}$, Alegría señalaba:

En primer lugar, Ios indios $\mathrm{y}$ cholos que aparecen en "El mundo es ancho y ajeno" y en todas mis novelas hablan en la vida real español. Son norteños y en su extensa región, excepción hecha del Callejón de Huaylas y la pampa de Cajamarca, no se parla en quechua más.

En general, todo el pueblo que pulula en mis libros, sólo mecha con cierto número de sobrevivientes palabras quechuras su habitual español tartajoso $y$, frecuentemente, arcaico.

Al novelar sobre esos mundos, cuanto hice fue pegar el oído a los recuerdos, tratando de captar el idioma de los norteños en su intenso colorido y su enorme fuerza expresiva.

10. Casi está demás advertir que este alejamiento nada tiene que ver con el que agostó

11. Cf. Escobar, Alberto: "Igenismo estctizante, de V. Garcia Calderón, por ejemplo. na de Cultura, Lima: 'La guerra sllenclosa de 'Todas las sangres' ", en: Rev. Perua. soclal como creaclón abril 1965, No 5 . Salazar Bondy, Sebastián: “Arguedas: la novela 1963, Vol. XIX, No 11.

12. Las declaraciones de 
Sintiendo una fundamental adhesión por la cultura norteña, he utilizado el lenguaje de mis paisanos en la forma que he podido y era la única que cabía, sin considerar que un preconcepto haria esperar que siempre los indios hablaran en quechua. (13)

Este “español tartajoso y (...) arcaico" es, entonces, el que se intenta reproducir en los relatos de los personajes. narradores y en los diálogos.

La novela se construye, pues, mediante un juego de distanciamientos y aproximaciones, con un trasfondo de reflejos múltiples pero elementales, que se resuelven en una comunidad que parecía imposible: la del lector y el narrador. $\mathrm{Y}$ esto es así sólo por la configuración idiomática de los relatos. Lector y narrador usan una misma norma; esto es, son de un mismo mundo y ambos se proyectan sobre una realidad ajena: la que sólo es propia del Simón Robles, la Antuca, los Celedonios, que no hablan en quechua pero que modulan una expresión lingüística diversa. Con esto deja de ser incómoda y estéticamente ineficaz la situación del lector. Pero resulta que el narrador puede explicar, y bien, lo que acontece en el mundo novelesco. Demuéstrase así que, siquiera por asimilación cordial, por vivencias no especificadas en la novela, pero de cuya existencia el lector no duda, el narrador se sitúa en ambos mundos y sirve de intersección entre uno y otro. El narrador resulta ser así una especie de intérprete y de testigo del mundo cordillerano: su postura, como antes la del lector, se hace también, a partir de aquí, estéticamente válida. Y comprendemos cómo, lo que pudo parecer un vicio estructural, se convierte en la clave de la configuración de "Los perros hambrientos"14.

Por lo demás, la divergencia entre las normas lingüísticas empleadas no afecta el tono de sencillez coloquial que preside el relato, confiriéndole una cordial fuerza apelativa, en la medida en que la norma de los narradores populares se acepta como un aspecto más del testimonio verista del narrador y no como la única posibilidad de presentar la rea. lidad del mundo novelado.

Es claro que esta comunidad narrador-lector, que hablan el mismo "idioma", y el tono de oralidad que importa un

13. "El idioma de Rosendo Maqui", en: "Expreso", Lima, 5-VI-1964.

14. Esta es una constante de la novela indigenista. Tal vez en los diversos grados de alejamiento (de más a menos) pueda encontrarse el senticlo de su evolución. 
clima de intimidad casi familiar, liquidan todo posible enfriamiento de la situación comunicativa de la novela y nos permiten acceder al. extraño y ajeno mundo andino ${ }^{15}$ con el ánimo apropiado para recibir sus vibraciones.

EL RELATO Y LOS RELATOS

El acontecimiento de "Los perros hambrientos" está constituido externamente por dos grandes corrientes narrativas: la que alude a las aventuras y penalidades de los personajes humanos y la que se refiere a "historias de perros", para utizar el título del segundo capítulo de la novela. Si nos atenemos a la confesión del autor, el planteo primitivo de la obra establecía la preeminencia de la segunda gran veta narrativa: "...y así una novela planeada sobre perros fue dando ingreso, página a página, a los hombres", nos dice Alegría en "La novela de mis novelas"16.

En la secuencia de la novela, sin embargo, ambas corrientes se cruzan, se vinculan y terminan por unimismarse, tanto, que es lícito pensar, con Estuardo Núñez, que "el título resulta válido, en un sarcasmo terrible, para los animales y también para los hombres"17.

Por otra parte, en sus dos estratos, el acontecimiento se desarrolla casi circularmente: desde la descripción de un ambiente de bonanza, aunque modesta:

La Antuca y los suyos estaban contentos de poseer tanta oveja. También los perros pastores. El tono triste de su ladrido no era más que eso, pues ellos saltaban y corrían alegremente... (p. 175)

hasta el esperanzado anuncio de una felicidad tal vez posible:

Wanka, Wankita... Has güelto como la lluvia güena... Y para Wanka las lágrimas y la voz y las palmadas del Simón eran también buenas como la lluvia... (p. 323)

Entre uno y otro extremo, acupando la mayor parte de la narración, aparece un personaje terrible: la sequía. Y con él,

15. Nos referimos a la situación comunicativa que emana de la construcción de la novela; no a la relacićn real que el lector tiene o puede tener con el mundo andino.

16. "Sphlnx", II, No 3. Esto se comprueba efectivamente en la novela. Por ejemplo, el la historia de Gueso

17. "La literatura peruana en el siglo XX", México, Pormaca, 1965, p. 126. 
en una suerte de danza macabra, el dolor, la miseria, el hambre, la explotación el odio y la muerte.

Dentro de este proceso general, y con magnitudes muy variadas, se interpolan considerables núcleos de acontecimien. tos marginales: algunos correlativos al asunto de la sequía, pero otros autónomos o semiautónomos con respecto a ese núcleo. Es imprescindible detenerse en este punto.

\section{LA SEQUIA}

Ya está dicho que la sequía ocupa gran parte del relato de "Los perros hambrientos"; concretamente, los capítulos VII, VIII y del X al XIX versan sobre este "tema". Sería ocioso detenerse en explicar que esta magnitud, en principio sólo cuantitativa, significa que novela tiene como núcleo básico la presentación de la sequía.

Pero lo que sí debe ser materia de análisis es el modo cómo el narrador plasma estilísticamente el fenómeno de la sequía, mucho más complejo de lo que pudiera suponerse, y las funciones que tal fenómeno cumple dentro del relato en orden a la representación general del mundo andino.

En lo que respecta al primer punto, el narrador arma su estrategia creadora en dos principios tradicionales: la antítesis y el retardamiento del desarrollo de la acción. Sabemos ya que la novela se abre presentando un clima de bonanza donde la felicidad es posible. El primer capítulo es, en verdad, un cuadro bucólico; la soledad y el silencio del paisaje, la tristeza de la quena, las eventuales tormentas, el frio y el aire helado, a lo más imponen un sabor de tierna melancolía a la escena. Pero allí está también el canto de la Antuca, sus primerizas dezasones sentimentales, la buena compañía del Pancho, la alegría de los perros y la seguridad de la manada numerosa:

Pero casi siempre retornaban a su lugar con tiempo calmo, en las últimas horas de la tarde, envueltos en la feliz policromía del crepúsculo (p. 181).

Este clima, que importa el primer extremo de la antítesis alegría-dolor, se va desdibujando paulatinamente en los dos capítulos siguientes: en el segundo, a la vez que se nos cuentan aisladas "historias de perros", de las que trataremos más 
adelante, el narrador nos descubre, aunque indirectamente, la violencia y el rigor de la vida en los Andes: Máuser muere destrozado por un petardo de dinamita, Tinto encuentra su fin en los colmillos de Rafles, perro guardián de la hacienda, etc. Sin embargo, el narrador se cuida bien de no exagerar los tonos sombríos. Aún no ha llegado el momento de la antítesis definitiva $y$, por eso, el capítulo se resuelve en un ambiente más bien risueño con la interpolación de un gracioso" cuento". El cuarto capítulo es muy similar, en sus intenciones, al segundo: se insiste en la dureza de la vida andina, esta vez graficada en la constante lucha de perros y pumas, pero tampoco se rompe el tono establecido en el primero. Aquí también esta unidad se resuelve en el relato de otra graciosa "historia".

El capítulo tercero es más complejo. Representa, por una parte, la reiteración de un tópico de la novela indigenista: el prepotente reclutamiento ("la leva") de los indios por la Guadia Civil; pero, por otra parte, significa el planteo de una situación específica (al ser reclutado Mateo Tampu quedan abandonados Martina, su esposa, hija de Simón Robles, el pequeño Damián y su hermano recién nacido) que, al desarrollarse, será la que imponga, en su máxima intensidad, la antítesis ya dicha. Sucede, empero, que esta función se cumplirá mucho más adelante, en el capítulo XVI, y, mientras tanto, la historia de Mateo Tampu tiende a aparecer como una más de las narraciones interpoladas.

Dentro de la preceptiva más tradicional, los cuatro primeros capítulos vendrian a constituir la "exposición" de la novela. Y la verdad es que cumplen las misiones clásicas de esta primera instancia: se describe el ambiente, se prepara el desarrollo del acontecimiento, se presenta a los personajes, etc. Pero esta línea es bruscamente cortada en los capítulos $\mathrm{V}$ y VI (que continúan en el IX), donde se narra el episodio de los Celedonios. La significación de esta historia, sin duda marginal, será materia de comentario posterior. La secuencia principal de la novela prosigue, entonces, en
el capítulo VII. En este punto, terminada ya la "exposición", aparece por primera vez la sequía. El narrador tiene especial esmero en presentarla como un proceso y en dosificar, retardando la culminación de la antítesis, los elementos negativos. Para esto último se insiste en una técnica ya conocida por nosotros: la narración de los primeros indicios de la sequía, tadavía no angustiosos ("...las lluvias escasearon pronto y las mieses de la mayoría de las chacras no lograron su pleni- 
tud"; p. 233) termina en el relato de un cuento jocoso. Su resultado es:

Rieron las cholitas, el Timoteo aprobó y la Juana enfurruñóse solamente porque estaba en su papel haciéndolo. Había retor nado el buen humor. Para que tuviera consistencia más realista, el Simón ordenó:

- Timoteyo, mañana matarás una oveja ... (p. 236).

El lector descubre, sin embargo, que este es un ambiente precario, que la amenaza de la sequia es real, y comienza a preguntarse, inquietamente, por el final de esta tregua. El retardamiento de la acción importa, en este caso, el acrecentamiento de la tensión narrativa. Las inquietudes del lector comienzan a cristalizarse en el capítulo siguiente, el VIII, donde por primera vez aparece claramente el fantasma del hambre y donde la muerte es ya una posibilidad inmediata: la muerte de los perros Shapra, Raya y Manolia cierra ese capítulo.

Pero cuando se piensa que la sequía va a desencadenarse, después de estas muertes que son como lúgubres presagios, el narrador cambia de nuevo el rumbo del relato: en el capíIX culmina el episodio de los Celedonios. Hay, pues, un nuevo suspenso.

El capítulo $\mathrm{X}$ nos depara sorpresas. Por una parte, el lector descubre que "ha pasadocun ano"' y que, al parecer, ha terminado la malāoépoca. En efecto ${ }_{0}$ se describe aquí una nueva siembra y reaparece, incluso intensificado, el clima de alegría del primer capítulo:

$\mathrm{Y}$ de los campos llegó, fresca y áspera, llenando todos los ámbitos, la promisoria fragancia de la tierra arada, húmeda y llena de simiente. (p. 266)

Es indudable que este capítulo tiene una función muy concreta: revitalizar el esquema de la antítesis. En efecto, el retardamiento de la acción, si bien crea suspenso, diluye la fuerza de la antítesis que estaba preparando el narrador. Y ahora sí, cumplicla con eficiencia la misión de la técnica de de retardar el suceso, puede irrumpir abiertamente la sequía y completarse el otro recurso técnico: la antítesis.

La sequía termina por imponerse, pues, definitivamente. Su brutal vigencia determina la transformación radical del mundo andino. A tratar esta materia están destinados todos 
los capítulos restantes, menos el último, cuyo asunto es, precisamente, el fin de la sequía y el retorino a los modos de ser, costumbres y valores tradicionales.

\section{LA SEQUIA Y EL MUNDO CORDILLERANO}

El narrador ha conseguido cumplir sus fines: la sequía es una presencia insoslayable, terriblemente cierta, y el lector queda encerrado dentro de esa situación opresiva y taladrante. Aunque elementales, los dos procedimicntos empleados por el narrador han demostrado su eficiencia. La antítesis, en orden a la intensificación de su segundo miembro (sequía= dolor), sobre todo; y el retardamiento de la acción principal, en lo que toca a la tensión e interés del relato, por una parte, según ya se ha visto, pero también con la función de permitir que el lector se adentre paulatinamente en el horror de la sequía y sus consecuencias, evitando una proposición abrupta de las circunstancias y valores que aquélla conlleva, lo que traería consigo más la repulsa del lector, ante la inmensidad de la tragedia descrita, que su conmovida participación.

Hablamos de la sequía y sus consecuencias. Pues bien: resulta que la sequia funciona dentro de la novela cono un poder cataclistico que transforma y quiebra cuanto cae den. tro de su ámbito. Estas modificaciones se van escalonando, haciéndose más complejas y de mayor magnitud, en un proceso de expansión incontrolable que scmejasla progresión de los círculos que nacen del impacto de una piedra en el agua.

En efecto, la sequía se presenta como un azote universal que a todos y a todo afecta:

Pero el dolor, el hambre y la muerte son azotes supremos. El cielo tornó a clespejar, la tierra a quedarse sin jugos y toda la vida a padecer. (p. 277)

Las plantas y los árboles se secan, desaparecen. Son las primeras víctimas: " ...y' las chacras fueron pronto sólo pardos mantos". (p. 279). Luego, los animales:

Las vacas $(\ldots)$ retornaban luego con las cornamentas más bajas y los costillares más pronunciados bajo la piel terrosa y opaca.

Las cabras (...) escalaban pedrones y riscos para pasear su inquietud por los campos a través de ojos azorados (...) Su 
encumbramiento sólo les mostraba en más nítida forma la extensión del azote.

Las ovejas, discretas, tirábanse a acezar a lo largo de las sendas ... (p. 281)

Sobre todo los perros:

... pero los perros se sintieron perdidos. En la mayoría de las casas su ración fue suprimida. Tuvieron que lanzarse a los caminos y aparecieron las primeras tropas deambulando sin sosiego tras su insatisfecho anhelo. (p. 283)

La progresión culmina en el hombre. Para él la sequia es un reto monstruoso: terminará por desquiciarlo y por quebrar todo su sistema de vida. Las relaciones entre don Cipriano Ramírez, el hacendado de Paucar, y sus colonos entrarán en crisis; los colonos desconfiarán y terminarán por abandonar a los comuneros de Huaira; Martina se verá obligada a desamparar a Damián, su pequeño hijo, etc. Sucede que la sequía significa una "situación límite" y que su impacto elementaliza al hombre. Se trata, escuetamente, de vivir; vivir, en tiempo de sequía, importa sólo una cosa: alimentarse. Leemos: ". . los tiempos trágicos son pródigos en resurrecciones. Y en aquellos de nuestra historia la zarpa reapareció" (p. 285).

El fenómeno es universal. Afecta primero a las instituciones y costumbres menos li sólidas. Entre hacendado y colonos ha habido una cierta comprension. Si no generoso, don Cipriano tampoco ha sido presentado maniqueamente; como encarnación del mal:

El hacendado frunció las cejas ante el nuevo problema. Pero era evidente que esos hombres necesitaban y, siendo de hecho sus colonos, estaba en el deber de protegerlos. Pertenecía a esa clase de señores feudales que supervive en la sierra del Perú y tiene para sus siervos, según su propia expresión, "en una mano la miel y en otra la hiel", es decir, la comida y el látigo. Ese era el momento de la miel.

- Bueno - dijo-, que don Rómulo les dé un almud de ceba. da y uno de trigo por cabeza... (p. 269)

La sequía termina con esta suerte de entendimiento consuetudinario, basado en la injusticia, pero aceptado y tolerado, al menos externamente, por todos. Se produce una asonada, 
mueren algunos indios y queda al descubierto la substancial inhumanidad del sistema:

- Váyanse, no hay nada, yo no puedo hacer nada - terminó don Cipriano.

- Váyanse -repitió don Rómulo.

La voz del Simón sonó ronca y firme:

- Patrón, ¿cómo que nuay nada? Sus mulas y caballos finos tan comiendo cebada. ¿No vale más quiun animal un cristiano? Y tamién ay tañ sus vacas, puntà grande, patrón. Bienestá que haga pastiar, que no le roben... Pero hoy es el caso que debe matar pa que coma su gente. Peyor que perros tamos... Nosotrus sí que semos perros hambrientos (...) Há. galo po su mujer y sus hijos... Si tienesté corazón en el pecho, patrón, conduelasé... Y si tiene pensar e hombre derecho, piense, patrón ... Con nustro trabajo, con nustra vida sian abierto tuesas chacras, sia sembrao y cosechao to lo que usté come y tamién lo que comen sus animales... (pp. 317$318)$.

Pero las consecuencias de la sequía son mucho más hondas. Afectan también a valores reales: a la solidaridad humana, por ejemplo. Llegan a Paucar, perseguidos y hambrientos, los comuneros de Huairaa Son aceptados y reciben generosa ayuda de los colonos.conforme se acentúa la sequía la generosidad decrece y, al final, sólo hay recelo y desconfianza:

Porque fuera de los que morían de hambre y eran devorados por cóndores y gallinazos, se comenzaron a perder vacas y luego, cuando éstas fueron vigiladas, los caballas y burros. Se decía que los huairinos los mataban a escondidas, en las quebradas, y se los comian. (pp. 310-311)

También se dislocan las relaciones del hombre con lo sobrenatural. El viejo y piadoso, el honrado Mashe, enloquecido por el hambre, roba el manojo de trigo que la imagen de San Lorenzo llevaba siempre en la mano:

... y el hombre huryó, con el manojo de espigas bajo el poncho, temeroso y alborozado como si llevara un tesoro... ( $p$. 303)

En la soledad de la puna hombres y perros, literalmente 
hablando, fraternizan. Los leales perros ovejeros de Simón Robles forman parte de la vida familiar. Sin embargo, cuando la sequía alcanza su más alto punto de desolación, cuando la comida no sólo escasea sino que es un deseo materialmente irrealizable, los perros inician una retrogresión y terminan por ma$\operatorname{tar}$ y devorar a las ovejas antes a su cuidado. Es, como se ha dicho hace un momento, el tiempo de la zarpa:

Comenzaron a deslindarse fronteras entre hombres y animales, y entre hombres y hombres, y animales y animales. (p. 285)

Fue corriendo y no quiso creer lo que pasaba. (Los perros) habían muerto una oveja y se la estaban comiendo. (Antuca) regañó a los perros, gesticuló, alzó la rueca, pero todo fue en vano. A sus gestos y voces respondían con gruñidos sordos y seguían atragantándose vorazmente. Ya no era la dueña quien daba de comer. Era la que quitaba. Wanka, inclusive, ladró enfurecida. (p. 286)

La cordialidad de antaño, esa ternura franciscana en las relaciones de hombres con animales, quedó destrozada. Antuca misma, el Simón Robles, todos, se convierten ahora en enemigos de los perros:

El Simón estaba sentado en el corredor. Llegaban (los perros) con los hocicos rojos y los vientres llenos, colgantes, ahitos. Tomo un grueso bordón que tenía a su lado y se les fue encima. Gritaron ellos huyendo ante los garrotazos y él soltó interjecciones y los persiguió, acompañado por toda su familia, que apareció rápidamente armada de leños. (...) Como para que no les quedara ninguna duda, les tiraron piedras, y la buena puntería del Timoteo se lució en las costillas de Wanka. (p. 288)

Los lindes entre animales y animales se habian marcado pronto (los perros matan a las ovejas); entre hombres y animales, acaban, terca y fieramente, de señalarse. En ambos casos se llegará hasta los grados más extremos: Pellejo devora el cadáver de Zambo (p. 314) y doña Chabela, que quería a Pellejo y admiraba sus habilidades, termina por herirlo malamente:

... Pellejo insistió en acercarse moviendo amistosamente la cola. Entonces doña Chabela, cuando lo turvo a buena distancia, cogió un tizón y rápidamente lo punzó con él en las cos- 
tillas. La carne quemada dio un breve chasquido y Pellejo huyó a todo correr, profiriendo alaridos. (p. 309)

El disloque final, el más trágico al mismo tiempo, es el que afecta a las relaciones individuales de los hombres entre sí. Al ser "levado" Mateo Tampu quedan solos Martina, su esposa, y sus dos pequeños hijos. El relato de esta situación ya ha sido analizado en páginas anteriores; se dijo, entonces, que a partir de ella al narrador le sería posible construir el segunde punto extremo de la antítesis que se desarrolla en toda la novela. En efecto, Martina, abandonada, hambrienta, decide ir en busca de comida y deja al pequeño Damián con la última oveja que les queda. Al niño le robarán casi de inmediato la oveja y pronto, cuando iniciaba el camino hacia la casa de Simón Robles, su abuelo, morirá de hambre:

- Mamá, mamá..., quiero mote, mamita... - dijo el pequeño. Y luego se quedó callado, cerrados los ojos y pálida la dema. crada carita trigueña. Mañú sintió, con la segura percepción de los perros, que había llegado la muerte. Y aulló largamente y se quedó al lado del cadáver, acompanándolo... (p. 297)

La horrible agonía y muerte del pequeño Damián significa el clímax trágico del relato.

\section{LA TERCA DIGNIDAD HUMANA}

\section{(") orge Puccineli Converso»}

En este sombrío panorama de dolor y muerte, cuando todos los valores parecen retroceder ante la necesidad primaria de sobrevivir, un solo acontecimiento viene a reafirmar la dignidad del hombre andino y su reciedumbre moral. Casi paralelamente al comienzo de la sequía se conocen Jacinta -hija del anciano Mashe- y Timoteo - hijo de Simón Robles-. Atormentado por haber robado el trigo de San Lorenzo, miserable y hambriento, Mashe no podrá sobrevivir a la sequía. Jacinta queda abandonada y piensa en Timoteo. Tal vez sea oportuno citar integramente este pasaje:

Andando, andando, la Jacinta recordó al Timoteo. Parecía bueno y fuerte. Siempre la habia mirado mucho. Pero precisamente por haberla mirado más de lo debido, no quiso ni pudo llegar a su casa. Pensó que debía sentarse al lado del sendero y esperar. El saldría y la vería. Podría entonces invitarla a pasar. Si no, ella seguiría su camino, aunque no fuera 
precisamente suyo ninguno. Todo tendría el carácter preciso $\mathrm{y}$ justo.

Y así lo hizo. En la espera, deploraba que su miseria no le hubiera dejado siquiera un poco de lana que atar a la rueca. (...) Pasó mucho rato, y al fin salió el Simón y volvió a entrar. Entonces apareció el Timoteo. Es que el padre le habia dicho:

- Ay ta sentada una pobre mujer... No tendrá ónde dirse...

Al Timoteo le dio una corazonada y, obediente a ella, fue a ver de quién se trataba. Y velay que era la misma Jacinta. Se le acercó y consiguió decirle:

$-¿$ Quiaces aquí?

Ella se quedó.mirándolo:

-Mi taita sia muerto.

Luego bajó los ojos. ¡Qué difícil momento! Si tan solo hubiera tenido un huso y un pequeño hilo que torcer... Se puso a mordisquear el filo del rebozo. El Timoteo pensaba que en su casa faltaba todo, y el taita ahora, quizá... Al fin se decidió y dijo las palabras justas:

\section{- Vamos pala casacinelli Conversom}

En el corredor estaba el Simón. Magro y pálido, el poncho parecía colgado de un palo. Los dos se detuvieron ante él hechos una sola pregunta inquieta. ¿Iría a negar? ¿Iría a decir: "Te quedas po la noche, pero te vas mañana?" El Simón aplacó la dureza de sus ojos sombrios y dijo a la Jacinta:

- Dentra. (pp. 304-305)

Con la pudorosa espontaneidad de Jacinta y Timoteo y con la hospitalidad de Simón Robles aparece en la novela, dentro del obsesivamente trágico contexto de la sequía, una escueta connotación positiva que es casi una desesperada apuesta en favor de la vida y que significa la decisión de conservar la dignidad del hombre en sus más elementales y esenciales instancias: el amor y la piedad. 


\section{LA LLUVIA Y EL MUNDO QUIETO}

Y de pronto, en medio de la desolación universal, se produce "el viejo y siempre radioso milagro" (p. 321). Sobre la aridez absoluta comienzan a caer las primeras gotas de lluvia:

Las primeras gotas levantaron polvo. Luego el pardo de la tierra tornóse oscuro y toda ella esparció un olor fragante. Se elevó un jubiloso coro de mugidos, relinchos y balidos. Retozaron las vacas y los potros. Y los campesinos dilataron las narices sorbiendo las potentes ráfagas de la áspera fragancia. Fulgían los relámpagos, retumbaban los truenos, el cielo entero se desplomó trepidando. Y fue la tormenta una larga tormenta de alegría. Tierra y cielo se unieron a través de la lluvia para cantar el himno de la vida. (pp. 321322)

Se cierra así el círculo del acontecimiento narrado en la novela, insistiéndose en el tono que definía su primer capítulo: el de la alegria y la esperanza. Cuando Wanka regresa a casa de sus amos ("retornaba para ocupar su puesto de guarda"; p. 323), se tiene la impresión de que una pesadilla ha terminado y que todo vuelve a sus habituales cauces. La sequía se cierra sobre sí misma, pasa a ser el recuerdo de un "accidente", marginal por tanto con repecto a la normalidad de la vida, mientras ésta, como acabamos de decirlo, recobra su ritmo y se proyecta hacia ámbitos harto menos sombríos.

Esta visión "finap produce una sensación de quietismo y solidez. El mundo andino, convulsionado por la sequí, pare. cia haberse quebrado irremediablemente, al ceder y dislocarse buena parte de sus estructuras básicas. Resulta, sin embargo, que esto no es así, que el mundo andino se restaura, pasada la sequí, sobre un modelo precedente y que se mantiene fiel a sus categorías primarias, negándose a la dinámica de una transformación que parecía implicada en la ecuación sequia= desastre. En efecto, la sequía había permitido comprobar la endeblez de ciertas estructuras; empero, esta comprobación se niega a ser experiencia y a convertirse en fuente de modifi. caciones futuras. En este sentido el desastre es, para el mundo andino, esclarecedor y estéril.

Por otra parte, la sequía, en cuanto fenómeno físico, es tajantemente a-histórico. Por consiguiente, sus resultados, las proyecciones de luz que expande sobre la índole de la vida cordillerana, se agotan en el sentido de la fatalidad inexplica- 
ble. El dolor y la miseria viene a ser no más que designios sobrenaturales, ajenos a la voluntad del hombre, a su conciencia actuante, y marginales en referencia a las fuerzas sociales en cuya dirección y sentido el hombre interviene. De aquí que, pasado el fenómeno físico, la vida histórica continúe su tono y ritmo seculares.

Sin duda las categorías de "lo fatal", con sus ramificaciones múltiples, y de lo "intransformable", también con diversas connotaciones, constituyen un todo. El lector de "Los perros hambrientos", lo percibe así desde muy al comienzo de la novela. Recordemos este párrafo:

Así son los idilios en la cordillera. Su compañero tenía, más o menos, la edad de ella. La carne en sazón triunfaria al fin. Sin duda llegarían a juntarse y tendrían hijos que, a su vez, cuidando el ganado en las alturas, se encontrarían con otros pastores. (p. 179)

De padres a hijos, interminablemente, la historia se repite, idéntica siempre. Hasta los sentimientos más íntimos son previsibles; previsibles aquí y ahora y también, lo es más sintomático, en el futuro de nuevas generaciones. Es difícil encontrar una imagen más clara de inmovilidad, de repetición, de solidez y quietismo de un mundo.

Pese a esta a-historicidad que define a la representación del mundo andino en "Los perros hambrientos", lo cierto es que la sequía sirve, como hemos visto, para iluminar ciertas dimensiones concretas de tal mundo, algunas de las cuales importan un acontecer y una conciencia históricos, como pudimos comprobar al aludir a la ruptura de ciertas estructuras sociales (episodio de la asonada). El problema reside en que este tipo de esclarecimiento parece no ser proyectivo; vale decir, permanece ligado y circunscrito a un accidente físico, sin capacidad para zafarse de ese círculo que, a la larga, puede ser desfigurante. En otras palabras: la restauración del orden precedente no permite trazar una dinámica horizontal, una secuencia transformadora, en la medida en que lo establecido bajo el imperio de la sequía termina, al parecer, conjuntamente con ésta.

\section{"QUIEN DEJA AL LADO LA LEY COMUN"}

La fábula central de la novela gira, como es obvio, sobre Simón Robles, su familia, sus perros. La historia de uno de 
éstos - Güeso- dá ingreso a uno de los episodios que diversifican la acción novelesca, al más largo e importante: el de los Celedonios.

A primera vista el de los Celedonios, aunque extenso, no pasa de ser un episodio marginal. Muchos indicios parecerían así comprobarlo; por ejemplo, la radical distancia que separa a los personajes del ámbito central y a los de este episodio, que ni siquiera se conocen, el cambio de ambiente: de la helada puna a las calurosas vecindades del Marañón, etc. Esto es así, sin duda, y hasta la historia de los hermanos bandoleros bien podría independizarse con entidad de relato breve (ocupa sólo los capítulos V, VI y IX), pero, por encima de las distancias obvias entre núcleo y episodio, existe una coherencia que tiene caracteres funcionales dentro del esquema estructural de la novela.

En efecto, los Celedonios representan un canon vital que discrepa intensamente con el de Simón Robles y los suyos. Aquellos viven al margen de "la ley común" (p. 232) y su mundo, lleno de aconteceres imprevisibles, es, en buena parte, hechura de su voluntad y decisión. Aunque parezca paradójica esta implicancia entre imprevisibilidad y voluntad, en cuanto una parece negar a la otra, lo cierto es que ambas se coordinan en este episodio. Julián y Blas, al igual que Güeso, se entregan "al incitante reclamo de la violencia" (p. 226). Al hacerlo así, aunque originariamente sueactitud devenga de una compulsión exterior, deciden vivir en permanente trance de aventura, escogiendo a cada paso sus acciones que son, al mis"mo tiempo, sus riesgos. Por consiguiente, estos personajes "hacen" sus vidas a través de cotidianos esfuerzos y decisiones. Sus actos, sin embargo, en cuanto son aventuras, escapan, en lo que toca a sus resultados, a sus previsiones. Al final se nos narrará la infame celada en que caen.

Ahora bien: esta capacidad de aventura que tipifica a los Celedonios, y su condición de hombres marginales, nos lleva a pensar que su historia constituye un segundo nivel testimonial con respecto al mundo andino, diverso y complementario del testimonio que nace de la vida de la familia de Simón Robles. La inmovilidad y el fatalismo cambian muy marcadamente de signo, tipificando así, por contraste con lo que sucede en el núcleo, la significación del episodio que nos ocupa.

Pero este contraste se hace más notable cuando se perciben los distintos y opuestos modos de relación entre los per- 
sonajes de la historia central y su sociedad y los personajes del episodio y esa misma sociedad. Los Celedonios, se ha dicho ya, deciden romper la "ley común". Con ello se marginan, hasta geográficamente, de su contexto social y sus relaciones personales o se proyectan sobre el ámbito muy reducido de otros bandoleros o, en caso contrario, se realizan dentro de un clima de peligro y muerte. Recordemos las visitas de Julián a Elisa. Aislamiento y rebeldía son, pues, consustanciales al modo de vida de los Celedonios. Todo lo contrario sucede con Simón Robles y los suyos. Porque la asonada en que participa Simón Robles no es, en realidad, más que eso: una asonada. Como tal no trasciende del concreto momento en que se realiza y no genera tampoco un tipo de conducta permanente. Ya hemos visto cómo, con el fin de la sequía, el mundo andino vuelve a la normalidad.

La rebeldía de Blas y Julián es permanente, sin duda; sin embargo, se agota en las categorías del acto individual. Claro que fue la estructura social la fuerza que los empujó al bandolerismo (cf. pp. 227-228), pero ellos mismos parecen no tener conciencia de tal situación y se limitan a vivir dentro de una circunstancia dada, acogiéndose a la vieja tradición andina del bandolero. De aquí que la significación de este episodio, pese a su diversidad con referencia a la que tiene el acontecimiento central de la novela, se resuelva en la sombría sensación que ya conocemos: la que emana de un mundo solidificado en la más desgarradora de las miserias. 